\title{
Kris Vassilev, Le Récit de vengeance au XIX siècle. Mérimée, Dumas, Balzac, Barbey d'Aurevilly
}

\section{Annalisa Bottacin}

\section{OpenEdition}

\section{Journals}

\section{Edizione digitale}

URL: http://journals.openedition.org/studifrancesi/7598

DOI: ERREUR PDO dans /localdata/www-bin/Core/Core/Db/Db.class.php L.34 : SQLSTATE[HYOOO]

[2006] MySQL server has gone away

ISSN: 2421-5856

\section{Editore}

Rosenberg \& Sellier

\section{Edizione cartacea}

Data di pubblicazione: 1 décembre 2009

Paginazione: 638-639

ISSN: 0039-2944

\section{Notizia bibliografica digitale}

Annalisa Bottacin, «Kris Vassilev, Le Récit de vengeance au xix siècle. Mérimée, Dumas, Balzac, Barbey d'Aurevilly», Studi Francesi [Online], 159 (LIII | III) | 2009, online dal 30 novembre 2015, consultato il 07 janvier 2021. URL: http://journals.openedition.org/studifrancesi/7598; DOI: https://doi.org/ERREUR PDO dans /localdata/www-bin/Core/Core/Db/Db.class.php L.34 : SQLSTATE[HY000] [2006] MySQL server has gone away

Questo documento è stato generato automaticamente il 7 janvier 2021.

\section{(c)}

Studi Francesi è distribuita con Licenza Creative Commons Attribuzione - Non commerciale - Non opere derivate 4.0 Internazionale. 


\title{
Kris Vassilev, Le Récit de vengeance au $\mathrm{XIX}$ siècle. Mérimée, Dumas, Balzac, Barbey d'Aurevilly
}

\author{
Annalisa Bottacin
}

\section{NOTIZIA}

KRIS VASSILEV, Le Récit de vengeance au XIX siècle. Mérimée, Dumas, Balzac, Barbey d'Aurevilly, Toulouse, Presses Universitaires du Mirail, 2008, pp. 212.

1 Intesa quale processo rituale in storie insolite e violente, la "vendetta", analizzata nei suoi processi e nei suoi meccanismi più inquietanti da Kris Vassilev, contrassegna l'indagine di questo volume che ha la peculiarità di analizzare dettagliatamente questo tipo di giustizia privata in quattro récits, che hanno le loro radici nella prima e nella seconda metà del XIX secolo. Lo studio attento di Vassilev esordisce comunque con una visualizzazione che impone una necessaria puntualizzazione sulle diverse caratteristiche dell'eroe della tragedia classica che, ferito nell'onore, ha quale ultimo fine la rapida risoluzione dell'offesa ricevuta, rendendo il suo atto estraneo a un premeditato effetto di vendetta. È quanto lo studioso delinea in «Prologue: vengeance et narration» (pp.15-67), in cui, con una serie di esemplificazioni, rileva l'esigenza di condensare la sua esegesi, preferendo alcuni testi ad altri, e facendo convergere, dunque, la sua analisi su due romanzi e su due novelle qui «se rangent [...] parmi les ouvrages les plus significatifs de l'époque, qui traitent du sujet» (p. 67).

2 Evidenziando quanto «la passion de la vendetta» sia radicata in un soggetto corso quale Colomba, protagonista dell'omonima novella di Mérimée, Vassilev inizia la propria esegesi e subito sottolinea quanto "cette vengeance archétypale» abbia suscitato un profondo interesse in epoca romatica tra un pubblico «en quête d'exotisme, de "couleur locale“ et de sensibilité primitive» («Colomba: La vengeance entre Classicisme et Romantisme», p. 71). In effetti, le novelle di Mérimée offrono sempre soggetti assai 
svariati e sembrano ben rispondere all'idea di proporre materiale insolito e talvolta non scevro da eccessi e non certo privo di una colorazione di esotismo. In particolar modo il classicismo di Colomba, la sua misura, il forte realismo non solo furono ben accolti da un'epoca impregnata di romanticismo ma fecero di Colomba un'innovazione nel genere della novella. Nominato nel 1834 Inspecteur des Monuments historiques, Mérimée, visitando in lungo e in largo la Francia e i suoi possedimenti, ebbe l'occasione di recarsi anche in Corsica; pare che egli stesso sia venuto a conoscenza di un episodio tragico al punto di tramutarlo ben presto in un récit, che tratta la lotta tra due famiglie rivali e che lo spirito cupo e fiero della giovane Colomba fa capitolare nel dramma. In effetti al ritorno del fratello, tenente dell'esercito napoleonico a Waterloo, lo induce a vendicare il padre ucciso da un emissario dei Borraccini, gli odiati rivali. La donna, rimasta chiusa a lungo nel suo proposito di vendetta, lo ha aspettato ansiosamente affinché faccia il suo sacro dovere; è questa attesa che ha pervaso la sua vita e che "peut expliquer le caractère scénique de la vendetta, sa théâtralité» (p.75). In effetti, qualora il vendicatore designato esiti a passare all'azione, sarà il resto della famiglia a rammentarglielo e ad imporglielo. «La vendetta - scrive Vassilev - se dessine ainsi comme une vengeance tant individuelle que collective, un acte qui correspond à l'attente des observateurs» (ibid.)

3 Il secondo récit preso in esame è Le Comte de Monte-Cristo («Vengeance et récit dans Le Comte de Monte-Cristo», pp. 105-133) di Alexandre Dumas père, pubblicato tra il 1844 e il 1845; lo studioso concentra la sua attenzione sull'opera vendicativa, spietata e terribile del protagonista, Edmond Dantès, diventato, allo scopo, il misterioso conte di Montecristo. Anche in questo caso la narrazione prende spunto da un «fait divers, enregistré dans les archives de la police de Paris par Jacques Peuchet» (p. 107), e lo stesso Dumas chiederà a Peuchet la sua collaborazione nella stesura del romanzo. Vassilev evidenzia subito come in trame in qualche modo rassomiglianti - ad esempio nel caso di Colomba - il protagonista a prima vista resti in ombra, necessiti di un nuovo nome (o più nomi) e di un cambiamento di stato per tessere la sua tela intorno a chi lo ha ingiustamente condannato a una lunga e dura prigionia, sottraendosi ad ogni occasione di svelamento anche con chi ha amato, un presupposto che viene accuratamente analizzato dal critico. Dantès, nel suo piano quasi diabolico, subisce una vera e propria metamorfosi, meglio varie metamorfosi, la prima di tutte sotto l'egida dell'abate Faria, anch'egli prigioniero dimenticato nell'isola di Montecristo: «Les incarnations multiples de Monte-Cristo sont renforcées par l'hermétisme dont il enveloppe volontairement son passé. Tout au long de la narration, - continue Vassilev le comte est unanimement qualifié de mystérieux, de singulier ou d'étrange par les autres personnages. [...] Si Monte-Cristo fascine et fait rêver, c'est parce que le secret de ses origines reste inviolable» (p. 121).

Il terzo récit preso in considerazione, il cui milieu social è quello della Francia di LouisPhilippe, è La Cousine Bette («La Cousine Bette ou la vengeance en échec», pp. 135-65), in cui Vassilev esordisce evidenziando quanto nel corso del xIX secolo il tema della vendetta abbia incontrato il gusto del pubblico e di un buon numero di scrittori in quanto, nota ancora il critico «l'acte de vengeance comporte une part de révolte contre l'ordre social. Et c'est justement parce qu'il vient immanquablement à bout de l'offenseur en imposant sa volonté personnelle que le vengeur "romantique" fascine» (p. 136). In La Cousine Bette, che Balzac redasse nel 1846 e che nella Comédie humaine crea con Le Cousin Pons la storia dei Parents pauvres (Scène de la vie parisienne), la figura della protagonista, Lisbeth Fischer, è quella della zitella inasprita che si nutre di invidie e 
gelosie verso i cugini che l'hanno sempre aiutata e protetta, insensibile ad ogni affetto. Il suo unico scopo è quello di vendicarsi per quello che nella sua vita non è riuscita a realizzare, portando così alla di-struzione amici e familiari, cadendo poi ella stessa miseramente. Nella sua interessante lettura, Vassilev rileva quanto la personalità pur contorta di Bette non faccia mai sospettare al prossimo le sue orride trame, in quanto si presenta debole, umile, inoffensiva, ben celando il suo lato pericoloso e crudele. «Cette position double, d'exclusion et de participation à la fois, - sottolinea lo studioso fournit les conditions favorables à l'exécution de sa vengeance» (p. 141). Una vendetta che assume un senso di grande modernità, visto che insieme ai personaggi del romanzo viene a svelarsi la società della Monarchie de Juillet con tutti i suoi giochi di potere, messi ben in mostra da Balzac. Come dire che la posizione sociale è alla base di tutta l'esistenza di Bette, che nel suo ruolo di vittima silente, riesce a operare intrighi pericolosi, proprio perché agisce di nascosto e la sua vendetta «concomitante des transformations qui remuent la société française de la première moitié du XIX siècle, se donne à lire comme une "vengeance-type", destinée à faire la synthèse de ces transformations et à en analyser les effets» (p. 163).

5 In una lettera a $\mathrm{M}^{\text {me }}$ Hanska, redatta il 28 giugno 1846, a proposito della scelta dei personaggi, Balzac scriveva: «Je vais me mettre sur La Cousine Bette, roman terrible, car le caractère principal sera composé de ma mère, de $\mathrm{M}^{\mathrm{me}}$ de Valmore et de ta tante Rosalie. Ce sera l'histoire de bien des familles». 